\title{
The Health Belief Model Applied to Understanding Diabetes Regimen Compliance
}

\author{
Marshall H. Becker, PhD, MPH \\ Professor and Chair \\ Department of Health Behavior and Health Education \\ School of Public Health \\ The University of Michigan \\ Ann Arbor, Michigan
}

\author{
Nancy K. Janz, RN, MS \\ Doctoral Candidate \\ Department of Health Behavior and Health Education \\ School of Public Health \\ The University of Michigan \\ Ann Arbor, Michigan
}

Inadequate adherence to prescribed treatment plans is perhaps the most serious obstacle to achieving successful therapeutic outcomes, and noncompliance by diabetic patients is no exception. This is partly based on patients' realization that compliance does not necessarily result in lack of illness. A psychosocial framework for understanding patient compliance is the Health Belief Model, which is based upon the value an individual places on the identified goal and the likelihood that compliance will achieve that goal. This Model has been useful to explain noncompliance, to make an "educational diagnosis," and for designing compliance-enhancing interventions.

Despite continuing advances in treatment approaches and technologies, effective control of diabetes is primarily dependent upon patient adherence to therapeutic recommendations. Typically, the diabetic regimen is "complex, of life-long duration, and requires many behavior changes on the part of the patient,"1 often involving "daily injections, urine testing, dietary modifications, safety measures, and exercise routines,"2 with each activity requiring the performance of many specific behaviors. It is therefore not surprising that studies of diabetic patients reveal disturbingly-low levels

Dr. Becker delivered the Keynote speech at the Eleventh Annual Meeting of the American Association of Diabetes Educators, September, 1984. of regimen compliance. For example, Watkins et al. ${ }^{3}$ reported that $80 \%$ of the patients studied administered their insulin in an unacceptable manner, $73 \%$ did not adhere to their diet plans, $50 \%$ did not engage in proper foot care, $67 \%$ did not correctly test their urine, and $45 \%$ tested and used the results in a manner likely to be detrimental to their diabetic control. Williams et al. ${ }^{4}$ found that approximately $50 \%$ of their diabetic subjects always displayed significant deficits in their food intake. More-recent studies have reported rates of regular urine testing as low as $30 \%,{ }^{5}$ and diet-regimen compliance in the 10-35\% range ${ }^{5,6}$ In perhaps the most detailed examination of adherence to different aspects of the treatment plan, Cerkoney and Hart ${ }^{1}$ obtained compliance levels of $81 \%$ for insulin administration, $77 \%$ for foot care, $65 \%$ for diet, and $57 \%$ for urine testing (only $7 \%$ of patients complied with all the steps considered necessary for good control).

The existence of such high levels of client noncooperation often surprises health workers, to whom such behavior may appear confusing and irrational. However, when viewed from the patient's perspective, the decision not to accept medical advice may be quite reasonable, particularly in light of the various effects on prevention or on treatment of different levels of regimen adherence (see Figure 1).

In our thinking about patient compliance, we usually imagine cases that fall in cells " $A$ " and " $D$ " in Figure 1; that is, achievement of the preventive or treatment goal simply depends on whether or not the individual follows professional advice sufficiently. In this manner, we tend to forget that a great many therapeutic incidents occur that fall in the two remaining cells of the Figure. For instance, one commonly encounters (and experiences) circumstances wherein faithful adherence to regimen does not yield the desired outcomes (i.e., cell " $\mathrm{B}$ "). The diagnosis may have been incorrect; the prescribed therapy may have been incorrect (or inadequate, or inefficacious); the patient may not respond to a particular treatment; the preventive measure may not have been sufficient; and so forth. Moreover, in the case of chronic conditions such as diabetes, even perfect compliance does not result in "cure" but rather in better control of the problem - and the highly cooperative patient is still vulnerable to untoward short-run (e.g., hypoglycemic episodes) and long-run (e.g., retinopathies) difficulties. The "lesson" learned (or attitude developed) by the individual is, "Sometimes, even if you do everything that health professionals tell you to do, you still get sick, feel sick, or don't get well."

One encounters similar learning experiences in cell " $\mathrm{C}$." Here, despite poor compliance, the patient nonetheless recovers (or does not become ill). Again the wrong diagnosis may have been made, or the symptoms may abate naturally. Much acute illness disappears without treatment, and socalled "risk-factor" behaviors (e.g., cigarette smoking, overeating, diets high in saturated fats and cholesterol) 
do not usually result in readily-observable illness in the short run. Some diabetic patients can deviate considerably from the prescribed therapy (e.g., overconsumption of carbohydrates) before experiencing manifest clinical problems (e.g., ketoacidosis). Nor does every risk taker become ill even in the long run. Here the "lesson" learned (or attitude developed) is, "Sometimes, if you don't do everything that health professionals tell you to do, you still get well/don't get sick." One is reminded of the contemporary relevance of Chapin's comment, made in 1915, that "the opprobrium of our art is that preventive medicine, like its other branches, has taught much that has had to be unlearned. We ought not to be surprised that people do not believe all we say, and often fail to take us seriously. If their memories were better, they would trust us even less."7

Thus, in light of the information and experiences just described, it is indeed not surprising that patients have developed a variety of health-related attitudes and beliefs affecting their decisions about both the necessity and the desirability of following professional advice. Added to these are the great variety of health beliefs learned from parents and peers and through personal experience.

The problem of patient noncompliance has been extensively studied; ${ }^{8}$ many correlations have been empirically identified (e.g., patients' knowledge levels, characteristics of the regimen, aspects of the provider-patient relationship) and relevant intervention strategies proposed. ${ }^{9}$ This article focuses on the contribution of patients' attitudes, more specifically on those contained in a model of individual health-related decision-making. This "Health Belief Model" (HBM) was originally formulated to explain why persons would or would not undertake preventive health actions, ${ }^{10}$ and was later applied to the prediction of compliance with prescribed therapies. ${ }^{11}$

\section{Dimensions of the HBM}

The basic components of the HBM are derived from a well-established body of psychological and behavioral theory, whose various models hypothesize that behavior depends mainly upon two variables: 1) the value placed by an individual on a

Figure 1

Relationships Between Client's Degree of Compliance and State of Health

\begin{tabular}{|c|c|c|}
\hline & $\begin{array}{c}\text { Illness Prevented } \\
\text { or } \\
\text { Successfully Treated }\end{array}$ & $\begin{array}{r}\text { Illness Not Prevented } \\
\text { or }\end{array}$ \\
\cline { 2 - 3 } $\begin{array}{c}\text { Adequate } \\
\text { Compliance }\end{array}$ & $\mathbf{A}$ & $\mathbf{B}$ \\
\hline $\begin{array}{l}\text { Inadequate } \\
\text { Compliance }\end{array}$ & $\mathbf{C}$ & $\mathbf{D}$ \\
\hline
\end{tabular}

particular goal; and 2) the individual's estimate of the likelihood that a given action will achieve that goal. ${ }^{12}$ When these variables were conceptualized in the context of health-related behavior, the correspondences were: 1) the desire to avoid illness, or if ill, to get well; and 2) the belief that a specific health action will prevent, or ameliorate, illness (i.e., the individual's estimate of the threat of illness, and of the likelihood of being able, through personal action, to reduce that threat).

Specifically, the HBM consists of the following dimensions:

Perceived susceptibility. Individuals vary widely in their feelings of personal vulnerability to a condition (in the case of medically-established illness, this dimension has been reformulated to include such questions as estimates of resusceptibility, belief in the diagnosis, or susceptibility to illness in general). ${ }^{9}$ Thus, this dimension refers to one's subjective perception of the risk of contracting a condition.

Perceived severity. Feelings concerning the seriousness of contracting an illness (or of leaving it untreated) also vary from person to person. This dimension includes evaluations of both medical/clinical consequences (e.g., death, disability, pain) and possible social consequences (e.g., effects of the condition on work, family life, social relations).

Perceived benefits. While acceptance of personal vulnerability to a condition also believed to be serious was held to produce a force leading to behavior, it did not define the particular course of action that was likely to be taken; this was hypothesized to depend upon beliefs regarding the ef- fectiveness of the various actions available in reducing the disease threat. Thus, a "sufficiently-threatened" individual would not be expected to accept the recommended health action unless it was perceived as feasible and efficacious.

Perceived barriers. The potential negative aspects of a particular health action may act as impediments to undertaking the recommended behavior. A kind of cost-benefit analysis is thought to occur wherein the individual weighs the action's effectiveness against perceptions that it may be expensive, dangerous (e.g., side effects, iatrogenic outcomes), unpleasant (e.g., painful, difficult, upsetting), inconvenient, time-consuming, and so forth.

Thus, as Rosenstock notes, "The combined levels of susceptibility and severity provided the energy or force to act and the perception of benefits (less barriers) provided a preferred path of action."13

The dimensions of the Health Belief Model are depicted in Figure 2. An impressive body of research findings now exists linking these HBM dimensions to compliance with regimens for hypertension, end-stage renal disease, middle-ear infection, asthma, and obesity, and involving such behaviors as taking (or administering) medication, following dietary restrictions, and exercise prescriptions, and keeping clinic appointments. ${ }^{14}$ Thus, it is reasonable to expect that the HBM would prove useful to our understanding of adherence problems in the area of diabetes and, in fact, several studies have attempted to apply the Model to explaining noncompliance by diabetics 
Figure 2

Basic Elements of the Health Belief Model

INDIVIDUAL PERCEPTIONS

MODIFYING FACTORS

LIKELIHOOD OF ACTION

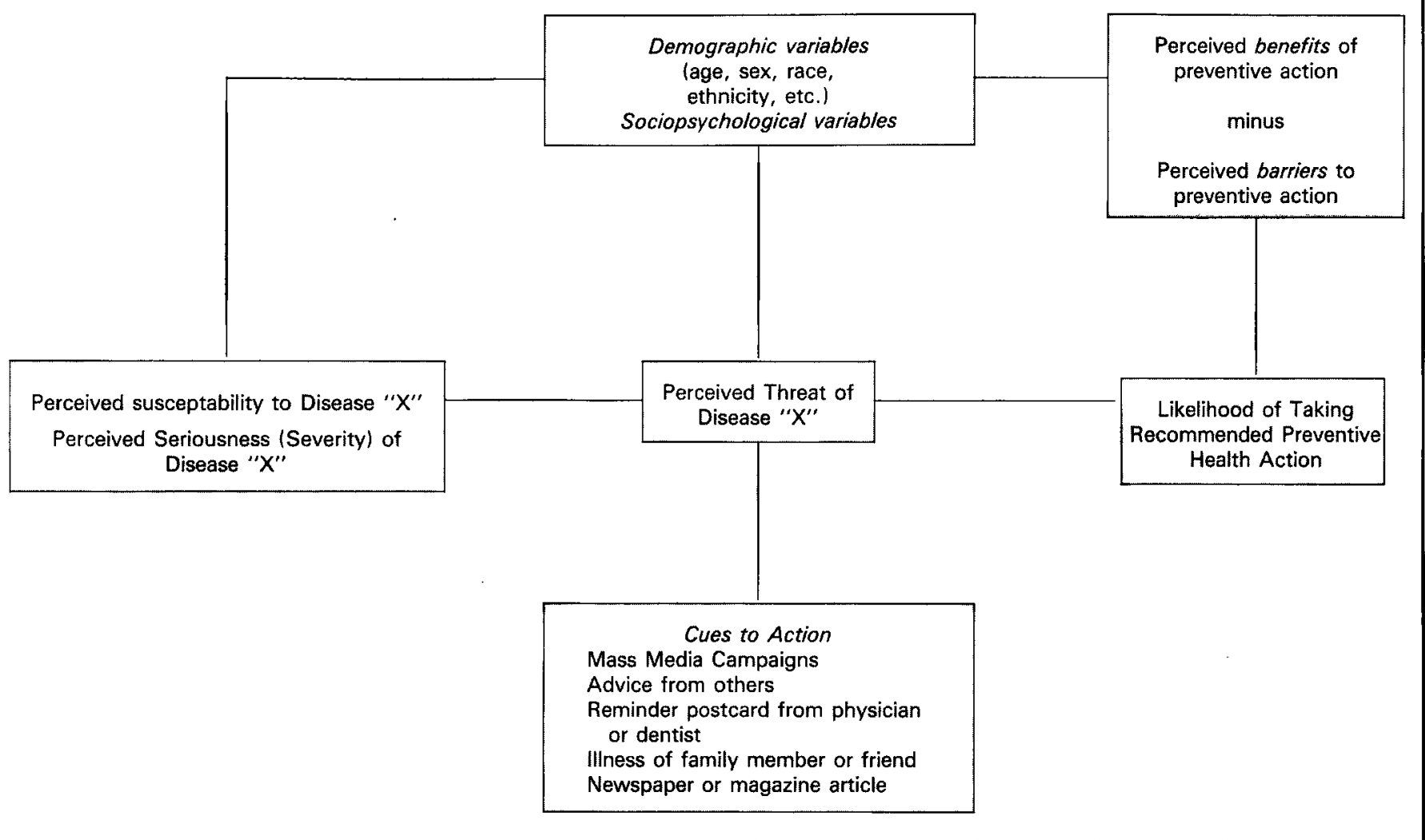

with their recommended therapies.

\section{HBM-Diabetes Studies}

In her study of adherence to a diet regimen for diabetes, Alogna ${ }^{15}$ examined the attitudes and behavior of 50 obese, noninsulin-dependent adult diabetics attending the Diabetic Clinic of Grady Memorial Hospital in Atlanta, Georgia. Forty-six of the patients were black, and 40 were female; 12 had their disease for one year or less, 30 had diabetes for 2-10 years, and eight had their disease for 11-26 years. Subjects were designated as "compliant" or "noncompliant" on the bases of prior weight loss and blood glucose control. The compliant group $(\mathrm{N}=25)$ included weight loss of 20-50 pounds in one year or less and loss of $10 \%$ of initial weight each year up to three years, with a random plasma glucose of less than $195 \mathrm{mg} / \mathrm{dl}$. Noncompliers either lost less than $10 \%$ of initial weight each year, or had an actual weight gain, with a random plasma glucose of more than 250 $\mathrm{mg} / \mathrm{dl}$.
Relevant to the HBM, Alogna focused on the single dimension of perceived severity of the condition. This dimension was measured by employing a "perception of severity of disease index" derived from a Standardized Compliance Questionnaire developed by Sackett and Haynes. ${ }^{16}$ This emphasis on "perceived severity" is understandable in light of findings from other HBM research showing that subjective estimates of the seriousness of the illness and/or of the sequelae of noncompliance are consistently associated with adherence to prescribed regimens. ${ }^{14}$

Results (Table I) revealed a significant difference on perceived severity: compliant subjects viewed their illness as more serious than did the noncompliant subjects. The authors note that "even though the individuals in the compliant group did not have more diabetes-related complications than non-compliant subjects, they perceived their diabetes as more severe. It may be that these patients are more realistic about the consequences of the disease and therefore are motivated to take action to control their diabetes."

Because this was a retrospective survey conducted with a small nonrandom group of patients at a single clinic, generalization of the findings must be viewed as limited. Also, because the investigator divided the dependent variable into only two categories, it is not possible to evaluate the role that perceived severity might play in explaining different degrees of regimen compliance.

Another study employing questions taken from the Standardized Compliance Questionnaire was conducted by Cerkoney and Hart, ${ }^{1}$ who interviewed 30 insulin-dependent diabetics 6-12 months after these patients had attended diabetic education classes at a community hospital. The subjects ranged in age from 18 to 73 years, with $80 \%$ over age 50 years. Twentyeight subjects were adult-onset diabetics, and almost half had been taking insulin for less than one year; the majority were white women with a high school education. Direct observa- 


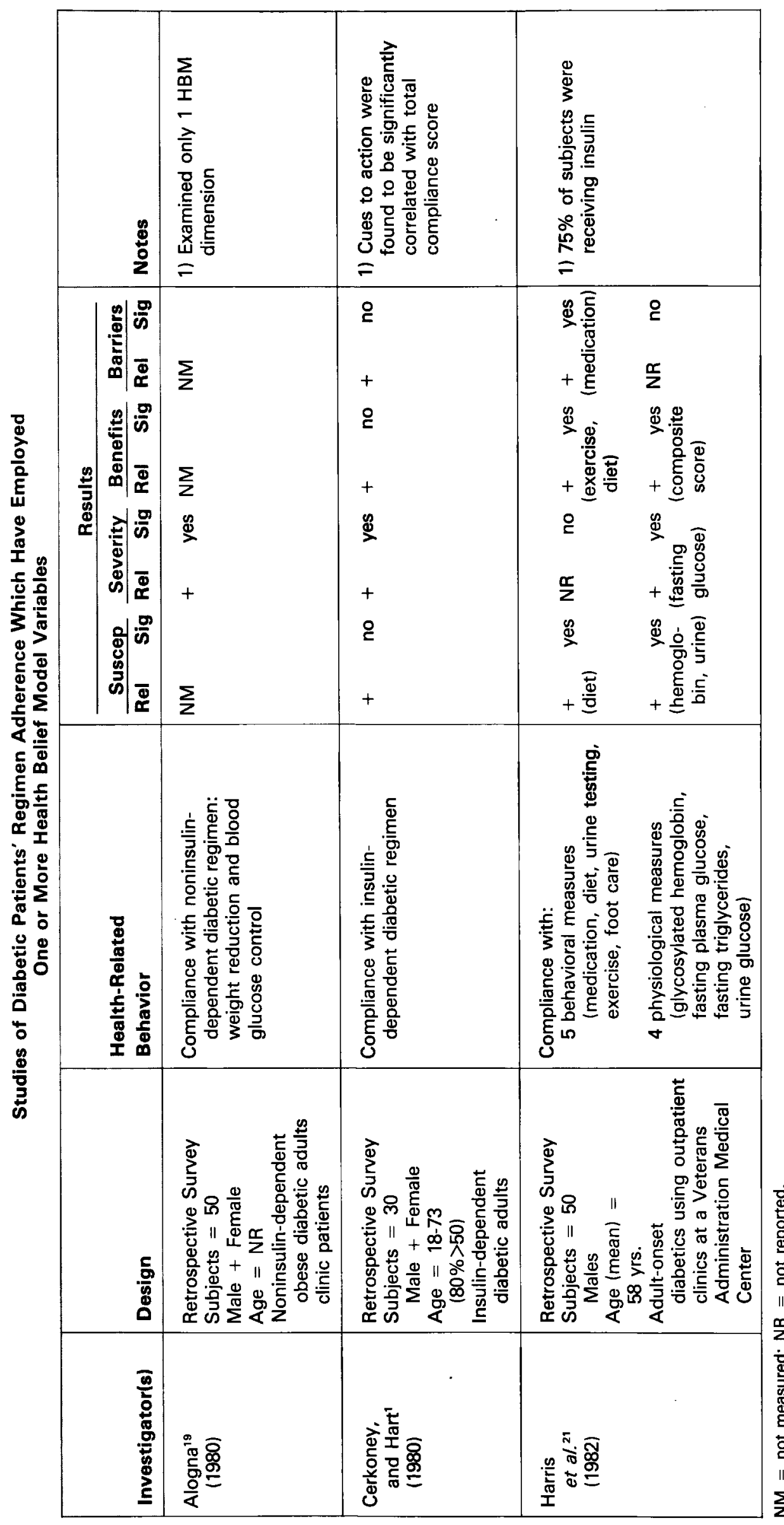

tion and self-report were used to assess levels of compliance in five areas: insulin administration; urine testing; diet; hypoglycemia management; and foot care. A total compliance score was constructed across these measures. Because the investigators were concerned about the validity of self-reports of adherence, items assessed by direct observation were given double point values.

The study questionnaire employed three items to measure each component of the HBM, with responses to each item obtained on a 5-point Likert-type scale. Interviews were conducted in the patients' homes.

As is evident from the data shown in Table I, results obtained using the total compliance score produced positive associations for each of the HBM components, and the correlation for "perceived severity" attained statistical significance. In addition, the investigators had also calculated a "total HBM score" across all HBM measures and the correlation between that score and the total compliance score was .50 (significant at $\mathrm{p}<.01$ ). Generalization of these findings is limited by the use of a small, nonrandom group of subjects, the retrospective nature of the study, and arbitrary doubling of the compliance scores obtained by direct investigator observation. An unusual feature of this research was the use of a highly-detailed multidimensional compliance score whose 61 items (across five regimen areas) included many aspects of the patient's regimen-related knowledge and behavior.

The most comprehensive exploration of the role of HBM dimensions in diabetes-regimen compliance was conducted by Harris and her colleagues. ${ }^{17}$ The study population was composed of 50 males with Type II diabetes, recruited from the outpatient clinics of the Miami Veterans Administration Medical Center. Seventy-five percent were white and $75 \%$ were married; only $20 \%$ were employed at the time of the study. These patients had a mean duration of diabetes of 10.7 years, and had been seen in the clinics a mean of 7.4 times during the previous year. The prescribed regimen included insulin for $75 \%$ of the patients; the rest were evenly divided between diet alone and diet plus sulfonylurea therapy.

Each subject was interviewed by a 
nurse who obtained 24-hour recall information in five areas of behavior: medication use, dietary compliance, urine testing, exercise, and foot care. Physiological measures of compliance included: glycosylated hemoglobin, fasting plasma glucose, fasting triglycerides, and urine glucose. Composite scores were also calculated for both the behavioral and the physiological measures. Subjects' health beliefs were obtained with a questionnaire containing 71 items, adapted from one used by Hartman and Becker ${ }^{18}$ in their research on compliance by chronic hemodialysis patients.

Significant correlations were obtained between: "susceptibility" and dietary compliance, "benefits" and exercise, and "barriers" and medication use. For the physiological measures, significant associations occurred between: "susceptibility" and both hemoglobin and urine glucose, "severity" and fasting glucose, and "benefits" and a composite score calculated across the four measures.

The investigators also found these health beliefs to be significantly associated with a number of sociodemographic variables. For example, married subjects were more likely to view themselves as susceptible to various complications of diabetes, and to feel it would have serious consequences for their family if they became sick. Black patients perceived themselves as less susceptible to complications, but were more likely to view medical care as beneficial. The younger the patient, the more likely there were to be psychological barriers to collecting and/or testing urine.

Study limitations include a retrospective design, a focus on a small, nonrandom sample of subjects (all veterans) and use of a composite score whose weighting scheme is not explained.

\section{Applying the HBM in Practice}

The perceptions and beliefs that make up the HBM have been demonstrated to be alterable. ${ }^{19-23}$ By determining which model elements are below a level presumed necessary for attaining compliance, the health-care provider should be able to tailor interventions to suit the particular needs of each patient. The following examples serve to illustrate ways in which HBM dimensions may be used as a basis for assessing and "treating" potential non- compliance by diabetic patients.

Beginning with "perceived susceptibility," the newly-identified diabetic not infrequently exhibits a reluctance to accept the diagnosis. Questioning by the health professional may reveal an erroneous health belief as a source of the problem (e.g., "I can't have diabetes, because I know that diabetes is inherited and there are no diabetics in my family"). Sometimes the patient searches for evidence to support alternative explanations for the symptoms (e.g., the mother of a recentlydiagnosed juvenile diabetic who observes that the child's insulin requirement appears to be decreasing and therefore questions the validity of the diagnosis). Having elicited these beliefs, the health educator can then intervene with corrective information and explanation le.g., on the diverse mechanisms of diabetes disease causation or about the "honeymoon period" often seen in the early treatment of the juvenile (Type I) diabetic].

With "perceived severity," any deviation from a moderate or "appropriate" level of concern signals the need for educational attention. On the one hand, the patient's estimate of the disease's seriousness may be relatively cavalier (e.g., "It's no big deal - they can treat anything nowadays"); on the other hand, the level of reaction to the diagnosis can be so extreme as to immobilize the patient (e.g., "I've heard that diabetics live terrible, restricted lives - I may as well give up"). Here, the educator can employ information, role models, etc., in attempts to raise or lower the client's subjective anxiety to bring it into a range appropriate for compliance motivation.

Sometimes the problem will be found to be the patient's lack of faith in the efficacy of one or more aspects of the treatment plan (e.g., "What good is the treatment that doesn't cure the problem?"; "I've heard that, even if I do everything they've told me to do, I will probably still have bad problems with my eyes or heart later in life"; "I don't think these pills help my diabetes"). In such cases, where the patient's perceptions of "benefits" are too low, the educator must direct interventions toward the proven value of the regimen to reduce the occurrence of acute crises in the short-run, to facilitate a higher quality of life and more-normal daily functioning, and to diminish the likelihood of (or post- pone) development of untoward disease sequelae in the long-run.

Finally (and perhaps most frequently), the educator may, upon interviewing the client, conclude that major threats to compliance will come from the diabetic's perception of "barriers" to carrying out different elements of the regimen (e.g., "My doctor says I should test my blood, but these finger pricks really hurt"; "What with shots, testing, watching what I eat, checking my feet - there's just too much to do"). In these instances, the educator must address each barrier with a unique intervention (for example, the educator could negotiate a plan with the patient that: reduces the number of different instructions (regimen simplification); orders the various elements of the regimen with regard to their importance (prioritizing the regimen); and perhaps builds the regimen up slowly over time (graduated regimen implementation) - in other words a set of recommendations designed to be both clinically sound and more acceptable to the patient. Many of these strategies can be incorporated effectively in provider-client contracts. ${ }^{24}$

We suggest, then, that the Health Belief Model provide the framework in which the diabetes educator can make an "educational diagnosis," making efforts to improve the diabetic's adherence to recommendations more effective by focusing them upon relevant identified attitudes and beliefs. Often, providing corrective factual information will prove sufficient; in other cases, motive-arousing appeals (e.g., fear, parental or family responsibility, pride), recommendations from other sources of information that have greater credibility to the patient (e.g., another patient for whom the regimen is successful), and other interventions will be necessary.

\section{Assessing the HBM Dimensions}

It is perhaps a testament to the model variables that, although they were measured somewhat differently in each study, they were still found to be associated with compliance. Nonetheless, standardized ways of measuring these psychosocial variables would facilitate evaluation and comparison of research findings, and would offer the practitioner a uniform tool for learning about patients' beliefs and attitudes. Important efforts directed at developing such scales and assessing their 
Table II

Sample Questions From Scales to Measure Beliefs of Diabetic Patients *(after Given et al. ${ }^{27}$ )

\begin{tabular}{|c|c|c|c|c|c|}
\hline \multirow[b]{2}{*}{ QUESTION } & \multicolumn{5}{|c|}{ RESPONSE SCALE } \\
\hline & $\begin{array}{c}\text { Strongly } \\
\text { Agree } \\
\text { (SA) }\end{array}$ & $\begin{array}{l}\text { Agree } \\
\text { (A) }\end{array}$ & $\begin{array}{l}\text { Undecided } \\
\text { (U) }\end{array}$ & $\begin{array}{l}\text { Disagree } \\
\text { (D) }\end{array}$ & $\begin{array}{c}\text { Strongly } \\
\text { Disagree } \\
\text { (SD) }\end{array}$ \\
\hline $\begin{array}{l}\text { Perceived Susceptibility } \\
\text { (sequelae of noncompliance) } \\
\text { My diabetes is well controlled. } \\
\text { My diabetes would be worse if I did noth- } \\
\text { ing about it. } \\
\text { I believe that my diet (medications) will } \\
\text { help prevent diseases (complications) } \\
\text { related to diabetes. } \\
\text { Diabetes can be a serious disease if you } \\
\text { don't control it. }\end{array}$ & $\begin{array}{l}\text { (SA) } \\
\text { (SA) } \\
\text { (SA) } \\
\text { (SA) }\end{array}$ & $\begin{array}{l}\text { (A) } \\
\text { (A) } \\
\text { (A) }\end{array}$ & $\begin{array}{l}\text { (U) } \\
\text { (U) } \\
\text { (U) }\end{array}$ & $\begin{array}{l}\text { (D) } \\
\text { (D) } \\
\text { (D) } \\
\text { (D) }\end{array}$ & $\begin{array}{l}\text { (SD) } \\
(\mathrm{SD}) \\
\text { (SD) } \\
\text { (SD) }\end{array}$ \\
\hline $\begin{array}{l}\text { Perceived Severity } \\
\text { My diabetes is no problem to me as long } \\
\text { as I feel all right. } \\
\text { My diabetes will have a bad effect on my } \\
\text { future health. } \\
\text { My diabetes will cause me to be sick a lot. } \\
\text { I believe I will always need my diabetes } \\
\text { diet (medications). }\end{array}$ & $\begin{array}{l}\text { (SA) } \\
\text { (SA) } \\
\text { (SA) } \\
\text { (SA) }\end{array}$ & $\begin{array}{l}\text { (A) } \\
\text { (A) } \\
\text { (A) } \\
\text { (A) }\end{array}$ & $\begin{array}{l}\text { (U) } \\
\text { (U) } \\
\text { (U) } \\
\text { (U) }\end{array}$ & $\begin{array}{l}\text { (D) } \\
\text { (D) } \\
\text { (D) } \\
\text { (D) }\end{array}$ & $\begin{array}{l}\text { (SD) } \\
\text { (SD) } \\
\text { (SD) } \\
\text { (SD) }\end{array}$ \\
\hline $\begin{array}{l}\text { Perceived Benefits } \\
\text { I believe I can control my diabetes. } \\
\text { I believe that my diet (medications) will } \\
\text { control my diabetes. } \\
\text { If I change my eating habits it will prob- } \\
\text { ably help me. } \\
\text { My medicine makes me feel better. }\end{array}$ & $\begin{array}{l}\text { (SA) } \\
\text { (SA) } \\
\text { (SA) } \\
\text { (SA) }\end{array}$ & $\begin{array}{l}\text { (A) } \\
\text { (A) } \\
\text { (A) } \\
\text { (A) }\end{array}$ & $\begin{array}{l}\text { (U) } \\
\text { (U) } \\
\text { (U) } \\
\text { (U) }\end{array}$ & $\begin{array}{l}\text { (D) } \\
\text { (D) } \\
\text { (D) } \\
\text { (D) }\end{array}$ & $\begin{array}{l}\text { (SD) } \\
\text { (SD) } \\
\text { (SD) } \\
\text { (SD) }\end{array}$ \\
\hline $\begin{array}{l}\text { Perceived Barriers } \\
\text { I would have to change too many habits } \\
\text { to follow my diet (medication). } \\
\text { It has been difficult following the diet pre- } \\
\text { scribed for me. } \\
\text { I cannot understand what the doctor told } \\
\text { me about my diet. } \\
\text { Taking my medication interferes with my } \\
\text { normal daily activities. }\end{array}$ & $\begin{array}{l}\text { (SA) } \\
\text { (SA) } \\
\text { (SA) } \\
\text { (SA) }\end{array}$ & $\begin{array}{l}\text { (A) } \\
\text { (A) } \\
\text { (A) } \\
\text { (A) }\end{array}$ & $\begin{array}{l}\text { (U) } \\
\text { (U) } \\
\text { (U) } \\
\text { (U) }\end{array}$ & $\begin{array}{l}\text { (D) } \\
\text { (D) } \\
\text { (D) } \\
\text { (D) }\end{array}$ & $\begin{array}{l}\text { (SD) } \\
\text { (SD) } \\
\text { (SD) } \\
\text { (SD) }\end{array}$ \\
\hline
\end{tabular}

* (after Given et al. ${ }^{27}$ )

validity and reliability have been successfully undertaken with regard to a variety of specific illnesses. ${ }^{25,26}$ However, the most recent (and extensive) attempt to construct and evaluate HBM indices has focused on measuring the beliefs of diabetic patients.

Given et al. ${ }^{27}$ derived their questionnaire items from three sources: 1) previous HBM instruments; 2) a review of educational materials for diabetics involving descriptions of patients' beliefs and reactions concerning their condition and regimen; and 3 ) in-depth, open-ended interviews with a convenience sample of 25 diabetics involving how these patients believed their condition influenced their lives, how the regimen helped to con- trol the disease, and what problems they had experienced in adhering to prescribed therapy. In all, the statements were developed to evaluate 12 concepts concerning patients' beliefs about their diabetes and regimen; almost all items were scored using a 5point Likert scale (from "strongly agree" to "strongly disagree"). These scales were administered to a sample of 156 diabetic patients drawn from 11 ambulatory centers in the Midwest, and the results subjected to factor analyses and tests of internal consistency. Scales thus derived were then cross-validated on a second sample of 92 diabetic patients, and subjected to tests for unidimensionality, internal and external consistency, and stability across both samples. The 12 initiallyhypothesized measures were ultimately reduced to six scales: 1) control of effects of diabetes; 2) barriers to diet; 3) social support for diet; 4) barriers to taking medications; 5) impact of job on therapy; and 6) commitment to benefits of therapy.

A table describing all 76 questionnaire items and their ultimate scale locations is provided by Given et al. ${ }^{27}$ By way of illustration (and to provide diabetes practitioners with examples of HBM questions they can use to make an "educational diagnosis"), 16 of Given et al.'s questions are reproduced in Table II. The patient should be asked to respond to these items along the following scale: strongly 
agree; agree; undecided; disagree; or strongly disagree.

These well-elaborated scales based on HBM dimensions should facilitate providers' attempts to assess diabetic patients' attitudes, and should enable more reliable and valid evaluations of interventions designed to alter patients' beliefs and subsequent compliance behaviors.

\section{Conclusion}

A large gap exists between realizing that health behavior is motivated and identifying the specific motivational components of a particular act. The Health Belief Model provides a useful framework of psychological variables that have been shown to be successful predictors of patient compliance, and which may therefore serve as a logical basis for educational interventions. ${ }^{14}$ This paper has described the core dimensions of the HBM, and has reviewed three investigations in which the Model has been applied to understanding regimen adherence by diabetic patients. Finally, we have noted the availability of scales to measure HBM-relevant beliefs of diabetics.

While the HBM emphasizes the need to be concerned with patients' attitudes and beliefs, the Model does not presuppose or imply any particular strategy for change. Thus, effective interventions may range from specific educational technologies delivered on a one-to-one or small group basis, through environmental and structural changes in the care delivery system, to social support systems and mass communication appeals. Throughout, we agree with Harris et al. ${ }^{17}$ that the HBM can serve "as a theoretical framework by which various groups of diabetic patients may be studied in relation to compliance," and that "the Model may be used as a basis for prospective studies of the effects of various interventions on health beliefs, compliance, and diabetes outcomes."

\section{References}

1. Cerkoney, K.A.B., and Hart, L.K. The relationship between the health belief model and compliance of persons with diabetes mellitus. Diabetes Care, 1980, 3:594-598.

2. Schafer, L.C., Glasgow, R.E., and McCaul, K.D. Increasing the adherence of diabetic adolescents. Journal of Behavioral Medicine, 1982, 5:353-362.
3. Watkins, J.D., Williams, T.F., Martin, D.A., Hogan, M.D., and Anderson, E. A study of diabetic patients at home. American Journal of Public Heaith, 1967, 57:452-459

4. Williams, T.F., Anderson, E., Watkins, J.D., and Coyle, V. Dietary errors made at home by patients with diabetes. Journal of the American Dietetic Association, 1967, 51:19-25.

5. Korhonen, T., Huttunen, J.K., Aro, A., Hentinen, M., Ihalainen, O., Majander, H., Siitonen, O., Uusitupa, $M$., and Pyorala, K. A controlled trial on the effects of patient education in the treatment of insulin-dependent diabetes. Diabetes Care, 1983, 6:256-261.

6. Christensen, N.K., Terry, R.D., Wyatt, S. Pichert, J.W., and Lorenz, R.A. Quantitative assessment of dietary adherence in patients with insulin-dependent diabetes mellitus. Diabetes Care, 1983, 6:245-250.

7. Chapin, C.V. Truth in publicity. American Journal of Public Health, 1915, 5:493502.

8. Haynes, R.B., Taylor,D.W., and Sackett, D.L. (Eds.). Compliance in health care Baltimore: The Johns Hopkins University Press, 1979.

9. Becker, M.H., and Maiman, L.A. Strategies for enhancing patient compliance. Journal of Community Health, 1980 , 6:113-135

10. Rosenstock, I.M. The health belief model and preventive health behavior. In Becker M.H. (Ed.), The health belief model and personal health behavior. Thorofare, New Jersey: Charles B. Slack, Inc., 1974, 27-59

11. Becker, M.H. The health belief model and sick role behavior. In Becker, M.H. (Ed.), The health belief model and personal health behavior. Thorofare, New Jersey: Charles B. Slack, Inc., 1974, 82-92.

12. Maiman, L.A., and Becker, M.H. The health belief model: Origins and correlates in psychological theory. In Becker, M.H. (Ed.), The health belief model and personal health behavior. Thorofare, New Jersey: Charles B. Slack, Inc., 1974 9-26.

13. Rosenstock, I.M. Historical origins of the health belief model. In Becker, M.H. (Ed.), The health belief model and person. al health behavior. Thorofare, New Jersey: Charles B. Slack, Inc., 1974, 1-8.

14. Janz, N.K., and Becker, M.H. The health belief model: A decade later. Health Education Quarterly, 1984, 11:1-47.

15. Alogna, M. Perception of severity of disease and health locus of control in compliant and noncompliant diabetic patients. Diabetes Care, 1980, 3:533-534

16. Sackett, D.L., Becker, M.H., MacPherson, A.S., Luterbach, E., and Haynes, R.B. The standardized compliance ques tionnaire. Hamilton, Ontario: McMaster University, 1974

17. Harris, R., Skyler, J.S., Linn, M.W., Pollack, L., and Tewksbury, D. Relationship between the health belief model and compliance as a basis for intervention in diabetes mellitus. Pediatric Adolescent Endocrinology, 1982, 10:123-132.

18. Hartman, P.E., and Becker, M.H. Noncompliance with prescribed regimen among chronic hemodialysis patients. Dialysis and Transplantation, 1978 , 7:978-985.

19. Haefner, D., and Kirscht, J.P. Motivational and behavioral effects of modifying health beliefs. Public Health Reports, $1970,85: 478-484$

20. Kirscht, J.P., and Haefner, D. Effects of repeated threatening health communications. International Journal of Health Education, 1973, 16:268-277.

21. Becker, M.H., Drachman, R.H., and Kirscht, J.P. A field experiment to evaluate various outcomes of continuity of physician care. American Journal of Public Health, 1974, 64:1062-1070

22. Becker, M.H., Maiman, L.A., Kirscht, J.P., Haefner, D.P., and Drachman, R.H The health belief model and prediction of dietary compliance: A field experiment. Journal of Health and Social Behavior, $1977,18: 348-366$

23. Sutton, S.R., and Eiser, J.R. The effect of fear-arousing communications on cigarette smoking: An expectancy-value approach. Journal of Behavioral Medicine, 1984, 7:13-33.

24. Janz, N.K., Becker, M.H., and Hartman, P.E. Contingency contracting to enhance patient compliance: A review. Patient Education and Counseling, 1984, 5:165-178.

25. Maiman, L.A., Becker, M.H., Kirscht, J.P., Haefner, D.P., and Drachman, R.H. Scales for measuring health belief model dimensions: A test of predictive value, internal consistency, and relationships among beliefs. Health Education Monographs, 1977, 5:215-230.

26. Jette, A.M., Cummings, K.M., Brock, B.M., Phelps, M.C., and Naessens, J. The structure and reliability of health belief indices. Health Services Research, 1981, 16:91-98.

27. Given, C.W., Given, B.A., Gallin, R.S. and Condon, J.W. Development of scales to measure beliefs of diabetic patients. $R e$ search in Nursing and Health, 1983, 6:127-141.

\section{Sustaining Members of AADE}

Ames Division

Miles Laboratories, Inc.

Becton Dickinson

Consumer Products.

Bio-Dynamics, Inc.

Diabetes Supplies, Inc

The Estee Corporation.

Flint Laboratories.

General Foods Corporation.

Kyoto Diagnostics, Inc.

LifeScan, Inc.

Eli Lilly and Company. Monoject.

Nordisk (USA)

Orange Medical Instruments.

Pfizer Laboratories.

Squibb-Novo, Inc.

The Upjohn Company. 